\title{
INTERSECÇ̃̃O DOS FEMINISMOS: ANÁLISES SOBRE A AGÊNCIA DA MULHER NOS PROCESSOS DE PROMOÇÃO DA PAZ NA SOMÁLLA
}

\author{
INTERSECTION OF FEMINISMS: ANALYSIS ON WOMEN'S \\ AGENCY IN PEACE PROMOTION PROCESSES IN SOMALIA
}

\section{RESUMO}

A Somália tem sido considerada pela sociedade internacional ao longo dos anos um dos países mais perigosos do mundo e o quinto pior lugar para ser mulher. Em meio ao caos da guerra civil que dura há mais de duas décadas, as somalianas ainda assim demostram, através de seus envolvimentos nos processos de promoção da paz e reconstrução dos aparatos estatais, que são agentes para além de vítimas. Por conseguinte, é objetivo do presente artigo analisar a agência feminina na Somália sob a perspectiva de três abordagens feministas: os feminismos pós-coloniais, africanos e islâmicos. Estas abordagens são substanciais para se entender o contexto local, além dos avanços e entraves nos direitos das somalianas, que foram colonizadas no passado pelos britânicos e italianos, e hoje observam o aumento do extremismo religioso no país.

Palavras-chave: Somália. Relações Internacionais. Promoção da Paz. Feminismos Pós-Coloniais. Feminismos Africanos. Feminismos Islâmicos

\begin{abstract}
Somalia has been considered by the international one of the most dangerous countries in the world and the fifth worst place to be a woman. Amidst the chaos of the civil war that has lasted for more than two decades, Somali women nevertheless are agents rather than victims through their involvement in the processes of promoting peace and rebuilding of state apparatuses. Therefore, this paper aims to analyze female agency in Somalia from the perspective of three feminist approaches: postcolonial, African, and Islamic feminisms. These approaches are substantial in understanding the local context vis à vis the advances and obstacles to the respect of Somalians' basic rights, which involves the country's colonization by the British and Italian Empires and today's increase of religious extremism in the country.
\end{abstract}

Key-Words: Somalia. Peace Studies. Post-Colonial Feminisms. African Feminisms. Islamic Feminisms.

Rafaela Julich Morais

UFSC. Email: rafaelajulich@gmail.com 


\section{Introdução}

O, Deeqa, estou realmente perdida

Quanto às verdadeiras intenções desta guerra.

Meu próprio povo está lutando uns contra os outros,

Os vizinhos estão agarrando ferozmente na garganta uns dos outros,

Minha situação não tem correspondência.

Minha roupa pegou fogo em ambos os lados,

E não sabendo nada de natação,

Fui levada pela corrente.

Da amarga árvore da'ar,

E o veneno fatal tem o meu preenchimento.

Por que as pessoas desse lado

Desprezam as pessoas do outro?

Por que os órfãos cansados devem fugir novamente?

As mães que estão sofrendo devem sofrer de novo?

Deeqa, estou realmente perdida. ${ }^{1}$

O Estado da Somália foi criado pela divisão da África pela Grã-Bretanha, Itália, França e o Império Abissínio durante a disputa pelo continente no século XIX. Formadas por tratados coloniais, as fronteiras da Somália hoje não se parecem com a distribuição do povo étnico somali que, além de predominar na própria Somália, habita terras vizinhas do chamado Corno da África (Quênia, Etiópia e Djibuti) (El Bushra \& Gardner, 2004).

A maneira como as nações europeias recaíram à Somália em sua disputa colonial por territórios deixou uma herança de fronteiras controladas artificialmente, que agora demarcam o Estado da Somália. A conferência de Berlim em 1884 inaugurou um período de eliminação das formas existentes de autonomia e a forma tradicional de autogoverno no país. Durante o período colonial, o território conhecido hoje como Somália era duas entidades distintas: o Protetorado Britânico da Somalilândia ao Norte e a Somalilândia italiana ao Sul (El Bushra \& Gardner, 2004). Os países colonizadores elaboraram linhas de fronteira que mutilavam unidades de parentesco (em outras palavras, os clãs) em fragmentos desconcertados (Rydlova, 2007).

A ocupação colonial e a divisão de território tornaram a Somália um país mais propenso à violência. $\mathrm{O}$ envolvimento militar externo contínuo na região dispôs os

\footnotetext{
1 Trecho de um dos mais famosos poemas para a promoção da paz, composto por Saado Abdi Amare, o qual foi recitado pela primeira vez publicamente sob a forma de protesto (baror) em 1994, durante o conflito na Somalilândia. Exprime a tristeza e a surpresa da poeta na renovação do conflito quando a maioria pensava que a guerra civil havia acabado. No original, em somali: Hadaba Deeqay dagaalkanu muxuи ahaa? Degelba degelkuu ku xigay daabcad kula kacyey, Shisheeye haduu is dilo waaba kala durkaa, Marada labadeeda dacal buu dab ii qabsaday. Hadaba Deeqay, dagaalkanu muxuи ahaa? muxuu daankaani daankaa ku diidanyahay? Intaan dacar leefay waabay durduurtayey, Dabaasha anoon aqoon daad I qaadayey, Agoonkii daalanaa dib uga caymadyey, Hooyadii weerku daashaday diboydayey, Dadkii iyo Hargeisaba is diidnayey, Berberadaan soo day idhi dib uga roorayey, Hadabaa Deeqay, dagaalkanu muxuu ahaa? Maxaa daankani daankaa ku didanyahay?
} 
somalis em lados opostos e aumentou o potencial de conflito da sociedade. As lealdades somalis para a administração britânica e italiana foram divididas, acrescentando outra dimensão ao conflito interno somalis. Quaisquer que fossem as diferenças no exercício de poderes, ambos os sistemas coloniais eram abusivos em relação às sociedades nativas. O colonialismo influenciou a sociedade somali em termos de reforçar e criar divisões de clãs. Mais importante ainda, as formas de governança tradicionais somalianas foram destruídas como resultado de fronteiras arbitrárias impostas pelo interesse econômico das potências coloniais, com desrespeito total aos laços de clãs tradicionais (Rydlova, 2007).

Em vista disso, a Somália tem sido considerada um dos países mais perigosos do mundo (Foreign Policy, 2009). Mais de um milhão de somalis permanecem deslocados internamente, enfrentando abusos por parte de grupos armados que limitam o acesso da população aos serviços mais básicos. Assim, o povo somali encontra-se preso em um fogo cruzado: embates entre operações militares externas, grupos armados como o Al-Shabab, e lutas entre os clãs por recursos resultam em novos deslocamentos e mortes de dezenas de civis diariamente (Human Rights Watch, 2016).

Tanto os homens quanto as mulheres vivenciam fenômenos similares durante conflitos armados; todavia, o modo como cada grupo experiência a violência é influenciado por seus papeis de gênero. A posição marginalizada da mulher na maioria das sociedades, acoplada à violência dos conflitos, acarreta a um aumento da vulnerabilidade deste grupo em tempos de guerra (Muzarana \& Proctor, 2013). Em 2016, mais de 7.00o casos de violência com base no gênero foram reportados na Somália, entre eles violência sexual, casamentos forçados e mutilação genital (PNUD, 2017).

Não obstante, é relevante demonstrar que as mulheres, mesmo em períodos de conflito, são agentes para além das vítimas. A mulher somali tem sido historicamente ativa nos processos de grande mudança política no país: desde as lutas anticoloniais até os movimentos de promoção da paz com o colapso do Estado após o estouro da guerra civil. Sendo assim, o presente trabalho visa analisar em especial a participação das mulheres somalis na esfera econômica e política da sociedade, buscando mover para além do rótulo de "Mulher do Terceiro Mundo" como sujeito singular, homogêneo e monolítico dos tradicionais estudos Ocidentais (Mohanty, 1988: 61), onde a mulher africana/latina/asiática é muitas vezes tratada exclusivamente como vítima da violência masculina.

Dado o exposto, é possível observar que, ainda que diante de momentos críticos da política do país (o colonialismo, o regime militar, a guerra civil e o colapso do Estado) e a estrutura demasiada patriarcal da sociedade, as mulheres foram capazes de atuar de forma enfática, influenciando e reconstituindo a história da Somália. Desta afirmação, surge a pergunta que o presente artigo buscará responder: diante da eclosão da guerra civil, quais são os principais mecanismos utilizados pelas mulheres somalis para exercerem sua agência no campo da política nacional? 
É objetivo central da pesquisa expor a agência feminina em tempos de conflito, em especial da mulher somali, movendo-se para além do rótulo de mulheres como vítimas da violência masculina generalizada. Este método de análise do papel da mulher como vítimas da guerra silencia a participação feminina nos conflitos, que podem ser diretamente envolvidas na luta armada ou fornecendo outros tipos de insumos aos esforços de guerra.

As mulheres podem tomar parte dos conflitos como mensageiras, enfermeiras, ou através de sua participação em movimentos políticos nacionalistas. Estão presentes, bem como, nas iniciativas de paz, que muitas vezes são baseadas em uma resposta pragmática a situações e não em uma orientação intrinsecamente pacifista (El Bushra, 2007). Sendo assim, mostra-se relevante superar as barreiras exercidas pelo rótulo de mulheres como apenas vítimas dos conflitos, pois ele ignora as complexidades da experiência das mulheres e nega-lhes a voz com a qual elas respondem às crises.

O artigo dividir-se-á em três seções principais: a primeira tratará da participação feminina nas lutas anticoloniais, no governo militar de Mohamed Siad Barre; a segunda, por sua vez, pretende expor a agência da mulher somali na promoção da paz na Somália após o estouro da guerra civil. Por fim, a terceira seção fará uma revisão teórica das correntes feministas pós-coloniais, africanas e islâmicas, que auxiliarão na análise do papel histórico da mulher somali na política e economia do país.

No intuito de se alcançar o objetivo proposto, os métodos de análises e procedimentos empregados pela pesquisa serão qualitativos, atentando-se ao estudo de caso da mulher na Somália e utilizando principalmente fontes secundárias. Ao expor aqui a agência feminina somali, buscar-se-á tomar o cuidado metodológico de não promover generalizações acerca da mulher como um grupo homogêneo e monolítico, além de prestar atenção ao contexto local específico da sociedade somali; com isso, intenta-se fugir do universalismo das teorias tradicionais de Relações Internacionais. Ademais, reconhecendo o standpoint distinto, além das diferenças de gênero, raça, etnia e posição geográfica entre a pesquisadora e objeto aqui estudado, não é intenção do trabalho "falar pela" mulher somali, mas dar visibilidade às as questões de gênero, raça, etnia e religiosidade que comumente são ignoradas na disciplina. Além disso, ter-se-á a cautela metodológica acerca das relações de gênero em uma sociedade, dado que é necessário levar em consideração os entendimentos locais sobre o significado de "gênero", "igualdade de gênero" e "inclusão". Para tanto, serão utilizadas teorias e abordagens somalis, e mais amplamente, africanas e islâmicas. 


\section{Agentes da própria história: a importância política e econômica da mulher somali}

O povo somali, como uma nação, compartilha um idioma, uma religião e uma história comum, o que os torna um grupo étnico único que habita uma grande área no Corno da África. Embora os somalis pertençam a um grupo étnico, eles derivam-se em grandes clãs, como: Dir, Isaq, Darod, Hawiye, Digil e Mirifle. Na era pré-colonial, a estrutura social e política dos somalis era menos hierárquica, mas o colonialismo europeu introduziu novos sistemas políticos e sociais mais centralizados (Adan, 2015).

Ainda que menos hierárquica, antes mesmo da colonização a sociedade somali era altamente patrilinear, onde mulheres e meninas eram designadas a um status inferior aos homens tanto na esfera doméstica quanto na pública. As mulheres eram tradicionalmente responsáveis por tarefas domésticas de encontrar e preparar alimentos para a sustentação da família, deixando pouco ou nenhum tempo para o envolvimento em decisões comunitárias ou para o fomento de sua educação (El Bushra \& Gardner, 2004).

Conquanto, de acordo com El Bushra \& Gardner (2004), as mulheres desempenham um papel vital na economia pastoral da Somália. Além das tarefas domésticas universais - os cuidados infantis e a preparação de alimentos -, elas também têm papéis importantes na criação de animais, o pilar da economia nacional. Elas empregam habilidades e conhecimentos técnicos consideráveis na construção e manutenção da casa nômade, bem como na elaboração de utensílios e recipientes e na administração de medicamentos naturais ao gado. $\mathrm{O}$ clima árido no país obriga mulheres e homens a adaptar seus papéis econômicos, e juntamente com o a guerra civil que afetou a sociedade somali desde 1988, a seca e o conflito desestruturaram famílias e exigiu que muitas mulheres assumissem a responsabilidade exclusiva de seus lares.

\section{Mulheres e movimentos anticoloniais na Somália}

Como argumentado por McClintock (1997), a imagem da mulher é geralmente associada à símbolos de portadoras da nação, ao mesmo tempo em que são negadas a qualquer relação direta com a agência nacional. Este parece ser o caso da história da mulher somali na construção da história do país, onde participaram ativamente dos processos de independência anticoloniais e diversos outros movimentos políticos relevantes à Somália. As mulheres têm sido historicamente incorporadas naquilo que alguns autores chamam de "metanarrativa nacional", onde elas entram na memória do país como sujeitas cuja agência é delimitada por seu significado metafórico e simbólico (Aidid, 2011: 104). 
A mulher torna-se, assim, significativa não como um ator politicamente engajado na luta nacionalista, mas sim como uma metáfora da tirania do colonialismo, onde nem mesmo as mulheres podem ser protegidas de sua violência (Aidid, 2011). Todavia, a mobilização política da mulher somali nas lutas pela independência da colonização foi de suma importância na promoção de uma consciência nacionalista na Somália. Aqui, mostra-se substancial a aplicação da teoria feminista pós-colonial para que seja possível a análise da agência feminina em tais processos.

Consoante a esta teoria, enquanto a teoria pós-colonial tradicional luta contra o discurso colonial dominante que busca deturpar o homem colonizado como inferior, a tarefa do feminismo pós-colonial é ainda mais laboriosa. De acordo com Tyagi (2014), a mulher sofre de uma dupla colonização, ou seja, ela simultaneamente experiência a opressão do colonialismo e do patriarcado. Nessa opressão, seu irmão colonizado não é mais seu cúmplice, mas seu opressor. Em sua luta contra o colonizador, ele até mesmo explora a mulher ao deturpá-la em seu discurso nacionalista. Por conseguinte, explorar as representações da mulher somali para além de um mero símbolo da "pátria mãe" é também demonstrar as formas como ela atuou ativamente nos movimentos políticos que construíram a Somália.

De todas as experiências somalis com o colonialismo, a Somália sob o mandato da Itália observou sua forma mais intervencionista e intrusiva. Houve uma ênfase no potencial agrícola do país, que apoiou muitas das políticas introduzidas neste período e marcaram o crescimento da economia de plantações e a quantidade de terra cultivada. Em contraste ao Protetorado Britânico da Somalilândia, a Somalilândia Italiana apropriou-se da terra e usou o trabalho forçado da população nativa desde o início. A concepção destas empresas agrícolas como concessões de exploração gerou uma política trabalhista de severidade considerável em teoria, e brutalidade real na prática. Era, de fato, indistinguível da escravidão (Aidid, 2011).

A fim de auxiliar o desenvolvimento da agricultura, a administração colonial italiana introduziu alguns regulamentos para facilitar a extração do trabalho nativo através da prática denominada asnikaax talyani (ou o casamento italiano), permitindo que os homens se casassem com as mulheres sem o consentimento delas ou de suas famílias (Aidid, 2011). Assim sendo, através da alienação das terras e políticas como o casamento italiano, o cotidiano das mulheres somalis e suas relações sociais foram profundamente afetadas pelos processos coloniais, em grande medida influenciados pelo viés do gênero.

Conforme apontado por Aidid (2011), a presença de uma grande comunidade italiana em Mogadíscio também circunscreveu a mobilidade dos somalis nas cidades através de práticas forçadas de segregação, o que impediu o acesso nativo a certos bairros, restaurantes, teatros e até calçadas. As mulheres em Mogadíscio, como suas irmãs na Somalilândia Britânica, não tinham acesso à administração colonial ou ao setor formal de comércio e educação. Considerando que nas áreas rurais o trabalho das mulheres pastorais era crucial para o grupo e a comunidade do clã, o trabalho das mulheres urbanas não recebia tamanha importância. 
Embora as mulheres somalianas das zonas urbanas fossem em grande parte invisíveis para o Estado colonial, sua natureza de gênero é mais uma vez destacada na sua presumida fonte de autoridade sobre elas. As mulheres estavam vinculadas ao projeto político de conter mudanças sociais na colônia e manter a lei e a ordem, mas ao fazê-lo, as autoridades coloniais institucionalizaram o patriarcado, deixando o controle das mulheres aos homens colonizados (Aidid, 2011). É possível observar aqui, portanto, um dos aspectos da dupla colonização sofrida pelas mulheres, como apontada pelas autoras feministas, sofrendo a opressão de ambos colonizadores e colonizados.

A principal forma de expressão utilizada pelas mulheres na Somália denominase buranbur, um gênero de poesia distintamente feminino que historicamente forneceu um meio socialmente aceitável para que elas se expressassem e protestassem. Uma cultura predominantemente oral, as tradições poéticas continuam a manter uma função social importante na vida cotidiana dos somalis, muitas vezes empregada como uma ferramenta pedagógica para comunicação, conscientização e preservação da história (Aidid, 2011).

Músicas para o trabalho, canções de ninar e outras formas de poesia buranbur forneceram uma plataforma para queixas e autoexpressão das mulheres, permitindo que elas articulassem suas preocupações através deste meio de comunicação aceitável. No entanto, a poesia das mulheres somalis assumiu um papel cada vez mais politizado e público com o surgimento do movimento nacionalistas para a independência após a Segunda Guerra Mundial. As mulheres produziram, articularam e espalharam a consciência nacionalista pelo país através de sua poesia (Aidid, 2011).

Sendo mais afetadas pelo domínio colonial e negadas mesmo às oportunidades limitadas abertas aos homens pelo governo colonial, na década de 1940 as mulheres na Somália sob a administração militar britânica se juntaram em massa ao movimento nacionalista com o mesmo entusiasmo e fervor que os homens. Conhecidas como as Irmãs, as somalis da Liga da Juventude Somali (LJS), durante as décadas de 1940 e 1950, estiveram envolvidas na organização e recrutamento de novos membros ao partido, promovendo sentimentos nacionalistas, arrecadando fundos e cobrando taxas de adesão, habitando e escondendo os nacionalistas das autoridades, e participando de manifestações (Aidid, 2011).

As Irmãs desempenharam um papel decisivo na promoção de uma consciência nacionalista através da composição da poesia, empregando a tradição feminina do buranbur para articular os discursos de solidariedade somali e instar a mobilização política de homens e mulheres. Nas reuniões locais da Liga da Juventude da Somália, onde questões de interesse político eram discutidas e debatidas semanalmente, a recitação da poesia patriótica tornou-se uma característica proeminente. O shir tradicional da Somália (que se traduz em reunião), onde a presença era limitada aos produtores autônomos masculinos que podiam exercer autoridade política e decisão para a comunidade, fora agora aberta para a participação das mulheres. O movimento nacionalista deu assim a elas a oportunidade de reivindicar uma participação na esfera pública tradicionalmente dominada pelos homens (Aidid, 2011). 
Com o fim da Segunda Guerra Mundial e ansiosos para receber a Itália de volta ao time ocidental, a Grã-Bretanha, a França e os Estados Unidos votaram em 21 de novembro de 1949 uma tutela das Nações Unidas para a Somália, sob administração italiana. Apesar das disposições firmes estabelecidas pelo acordo de tutela da ONU, a nova administração italiana tinha em grande parte o caráter de uma ocupação militar, e muitos funcionários e administradores italianos que haviam servido sob o regime fascista retornaram aos devido suas experiências durante o período colonial (Aidid, 2011).

Enquanto a Liga da Juventude da Somália e outras organizações nacionalistas não foram banidas como teriam sido na Somalilândia italiana, os nacionalistas que eram considerados "perigosamente anti-italianos" eram frequentemente presos ou deportados (Aidid, 2011: 115). Com a Liga da Juventude da Somália transformando-se em um partido político organizado em preparação para a independência da Somália, as Irmãs exigiram uma seção feminina no partido, ameaçando retirar seu apoio caso sua participação institucional fosse proibida. As somalianas se comprometeram com a causa nacionalista, sua poesia refletindo e produzindo consciência política, mas agora encontravam-se fora das instituições políticas e estatais pelas quais lutaram e as histórias nas quais foram atores críticos (Aidid, 2011).

A República da Somália foi finalmente fundada em 1 de julho de 1960 com a unificação das Somalilândias britânicos e italianos em uma onda de entusiasmo popular. A Liga da Juventude Somali, agora um partido político na nova República, elegeria os dois primeiros presidentes da Somália e dominaria as eleições até o golpe militar do general Mohamed Siad Barre em 21 de outubro de 1969. Nenhuma mulher entraria no parlamento sob os governos da LJS, e muitas se veriam impedidas de ocupar cargos governamentais pelos quais elas eram qualificadas (Aidid, 2011).

Muitas somalianas falam com ressentimento e frustração quando perguntadas se sentiram que sua participação fora ignorada, descrevendo como as mulheres tinham feito o trabalho pesado para alcançar a independência, apenas para serem descartadas quando o objetivo foi realizado (Aidid, 2011). Desiludidas pela falta de vontade do Estado em abordar as preocupações das mulheres ou fornecer espaços para sua participação institucional, surgiram numerosos grupos de mulheres logo após a independência. O grupo feminino mais radical, o Movimento das Mulheres da Somália, foi fundado em 1967 com o objetivo explícito de "unificar e fortalecer a energia coletiva das mulheres somalis" e "educar o público sobre direitos básicos e garantidos constitucionalmente acerca da igualdade completa dos sexos" (Aidid, 2011: 117).

Essas organizações chegaram a um fim abrupto com a proibição do governo militar de Barre de organizações sociais e políticas. O regime de Siad Barre marcou um novo capítulo no discurso sobre gênero e status da mulher na sociedade somali. Colocou o fim da politização orgânica e da autoconsciência experienciada e articulada pelas mulheres somalis durante o período de luta anti-colonial e pelos grupos de mulheres que surgiram durante os primeiros anos da independência, agora invisíveis pela metanarrativa sobre a história da Somália (Aidid, 2011). 


\section{Governo militar de Siad Barre: uma agenda feminista?}

No intuito de justificar o descaso com as somalianas que auxiliaram na independência do colonialismo, o governo recém-eleito argumentou que as estratégias relacionadas à igualdade de gênero na sociedade não seriam suas principais prioridades. Havia um sentimento forte entre as feministas somalis de que os papéis domésticos das mulheres estavam sendo reafirmados, enquanto o poder político permanecia no domínio dos homens após a independência (Jibril, 2008). No entanto, elas continuaram a exigir que o poder político fosse compartilhado igualmente entre ambos os gêneros.

Isso mudou após a chegada do presidente Mohamed Siad Barre em 1969, que derrubou o governo civil democraticamente eleito, porém considerado corrupto (Horst, 2017). O regime revolucionário adotado por Siad Barre introduziu o socialismo científico que foi progressivo em algumas áreas - por exemplo, ao fomentar campanhas de alfabetização e propor a emancipação das mulheres da exploração capitalista -, mas introduziu um alto grau de controle estatal centralizado (Horst, 2017). Como o movimento nacionalista anticolonial, o Estado socialista identificou as mulheres da classe urbana como uma base forte de apoio e mobilizou-as de duas formas notáveis: com o Hooyoyinka Kacaanka (ou seja, "Mães da Revolução") e na forma da Organização Democrática da Mulher Somali (ODMS), que tinha filiais em todo o país (Mohamed, 2015).

Como apontado por Bryden \& Steiner (1992), Siad Barre via as somalianas como uma fonte atraente de legitimação de sua autoridade e consolidação de seu poder em nível de hegemonia estatal absoluta. Suas políticas em direção às questões de gênero podem ser resumidas em três segmentos: primeiro, Siad Barre desejava aumentar sua reputação global sob a bandeira da equidade de gênero; segundo, seu objetivo era usar as mulheres como um instrumento para mobilizar o público em apoio e legitimidade de seu regime no longo prazo; terceiro, ele pretendia "acelerar a substituição do direito consuetudinário e religioso por práticas jurídicas seculares" (Bryden \& Steiner, 1998: 31).

Embora o presidente nunca referisse a suas políticas como feministas, Mohamed (2015) alega que o avanço do direito da mulher foi uma importante plataforma retórica para o Estado. Fazia parte da ideologia socialista revolucionária que o governo adotou após a tomada do poder em 1969. Uma de suas políticas, direcionada às Mães da Revolução, foi um tipo de organização de mulheres através da qual expressavam seu apoio ao regime e ao líder. Referir-se às mulheres como "as mães da revolução" era uma forma de discurso nacionalista inerentemente enviesado pelas relações de gênero (Mohamed, 2015: 4).

É possível perceber a corporificação da nação no imaginário dos nacionalistas através da construção da "Pátria Mãe" ou da nação como uma mulher a ser protegida pelos "bravos cidadãos-guerreiros", tornando-se uma metáfora comum dos nacionalismos (Banerjee, 20031: 168) e presente no discurso de Siad Barre. Como nota 
Banerjee (2003), o viés de gênero no qual a imagem do homem é construída dentro de narrativas nacionalistas, bem como a noção de que as mulheres incorporam a honra nacional, influencia o modo como se dará a participação feminina na política nacional.

Siad Barre era conhecido como aabe, ou "o pai", e as somalianas eram simbolizadas como mães da nação. Com o pai como chefe da família ou da nação, a mãe - e, portanto, as mulheres - era relegada a um papel secundário ou reprodutivo (Mohamed, 2015:4). É com um exame mais aprofundado dessas narrativas patriarcais construídas pelo Estado que as discrepâncias e contradições entre o ideal - ou as noções atuais de igualdade de gênero - e aquilo que o governo promovia tornam-se evidentes, e podemos observar a utilização da mulher como peão no jogo político da Somália.

Essas mulheres do Hooyoyinka Kacaanka participaram de um intercâmbio sabático em que evitavam o confronto com a liderança do Estado militar para que fossem percebidas como aliadas, recebendo assim admiração e apoio do regime em troca. De acordo com Mohamed (2015), o objetivo era trabalhar dentro do sistema para garantir que não houvessem choques com o governo, a fim de que suas vozes fossem ouvidas. Para um Estado que punia severamente todos seus inimigos e que se empenhou em promover os direitos das somalianas, essa era uma escolha estratégica para obter alguma atuação política (Mohamed, 2015). Desta forma, ainda que em certa medida fossem manipuladas pelo governo através de simbolismos patriarcais, as mulheres foram capazes de também jogar no tabuleiro estatal.

Em um âmbito mais politizado, a divisão feminina do Estado foi criada em 8 de março de 1977 - dia internacional da mulher -, através da Organização Democrática da Mulher Somali, chefiada por mulheres da elite urbana que eram escolhidas pelo governo. A organização não era uma entidade independente; a influência do Estado dominou a agenda da ODMS, que funcionava de acordo com questões que a administração priorizava como relevantes para os direitos das mulheres. Além disso, e mais prejudicial ainda, "o governo militar usou a ODMS como uma ferramenta para controlar as somalis" (Mohamed, 2015: 4). Como o Hooyoyinka Kacaanka, a Organização Democrática da Mulher Somali era outra maneira de mobilizar o apoio feminino e legitimar as políticas estatais.

Não obstante essas inconsistências, é possível observar que as políticas estatais de Siad Barre ofereceram benefícios tangíveis às mulheres. Mohamed (2015) e Horst (2017) mostram que reformas importantes incluíram a licença maternidade com salário, uma forte ênfase estatal na educação de meninas, além de cuidados de saúde gratuitos. $\mathrm{O}$ acesso feminino à educação, emprego remunerado, benefícios sociais e participação política aumentaram durante este período (Mohamed, 2015; Horst, 2017). Outras reformas significativas e neutras quanto ao gênero incluíram o ensino primário obrigatório gratuito, a campanha de alfabetização de 1974-1975 e a redação da língua somali, que ajudou a avançar a alfabetização no país. Mais meninas foram para a escola sob o governo de Siad Barre que em qualquer outro período da história do país (Mohamed, 2015). 
O socialismo científico de Siad Barre forneceu uma forma efetiva de "feminismo estatal" (Horst, 2017: 4). As somalianas estavam envolvidas em todas as áreas da sociedade, e centros de orientação foram estabelecidos nas cidades de todo o país para encorajar as mulheres a ouvirem palestras, cantar canções revolucionárias e denunciar relacionamentos abusivos. Estes desenvolvimentos, argumenta Horst (2017), foram promovidos de várias maneiras por grupos que estavam interessados em direcionar a sociedade a uma maior igualdade para as mulheres. As ideias de Siad Barre sobre o socialismo estimularam a promoção de maiores liberdades para as mulheres, principalmente devido ao apoio de países europeus que também corroboravam as ideias comunistas (Daud apud Horst, 2017).

A igualdade de gênero e a participação política feminina, no entanto, continuaram sendo uma questão contenciosa em uma sociedade altamente patrilinear e conservadora. A promulgação da Lei da Família em 1975, que desafiava os princípios fundamentais do xeer e da sharia, e dava às mulheres direitos iguais no casamento, divórcio e herança, foi um excelente exemplo deste embate (Horst, 2017). Embora a lei fosse a culminação da luta do movimento de mulheres e fosse a peça legislativa mais importante para a igualdade de gênero, ela era altamente controversa.

A introdução da lei provocou protestos severos da comunidade islâmica, aos quais o regime respondeu executando dez líderes religiosos no início de 1975. Barre repreendeu a direita religiosa por criticar suas ações para melhorar os direitos das mulheres e, assim, minou fundamentalmente o movimento político feminino (Mohamed, 2015). A partir do descontentamento com o regime de Siad Barre, o contra-movimento liderado pela direita religiosa se intensificou. A sociedade somali percebeu o novo conservadorismo como "um desafio à liberdade de movimento, associação e vestuário, um desafio à autonomia que as mulheres herdaram de sua cultura nômade e transplantaram para os centros urbanos" (Horst, 2017: 5).

Por outro lado, enquanto as somalianas foram encorajadas a desempenhar um papel no movimento das mulheres, elas não receberam posições formais no governo de Siad Barre. Além disso, o clima geralmente repressivo e a manipulação da sociedade civil pelo regime, que se concentrou em manter o controle político a todo custo, também afetaram as associações de mulheres somalis. Ao mesmo tempo, o crescente papel público das somalianas e sua participação política levaram a contrarreações não apenas em setores religiosos conservadores da sociedade, mas também entre muitas mulheres de classe média e baixa (Horst, 2017).

Em suma, a promoção dos direitos das mulheres pelo Estado socialista de Siad Barre foi um movimento político para marginalizar seus inimigos domésticos, fortalecer seu relacionamento com a base de apoio feminina e melhorar a imagem da Somália no exterior. No entanto, apesar dos mecanismos políticos e legais existentes, na maioria dos assuntos, as somalianas trabalharam "em torno do Estado" para promover seus interesses (Mohamed, 2015: 8).

Vemos, portanto, o modo como a representação das somalis como "mães da nação" pressupõe que elas são capazes de desempenhar múltiplos papéis, e por isso podem ser úteis para moldar a retórica política que visa trazê-las para o conflito 
nacionalista (Banerjee, 2003: 177). Fica evidente que o uso pelo Estado somali desta retórica paternalista durante o regime militar serviu para mobilizar o apoio feminino aos propósitos políticos do governo. Ainda que este discurso reforce os binarismos de gênero e as noções socialmente construídas de masculinidade e feminilidade, através da atuação feminina em instituições como o Hooyoyinka Kacaanka e a Organização Democrática da Mulher Somali, percebe-se que elas foram agentes que se moveram para além do rótulo de mulheres como vítimas da opressão masculina.

\section{Para além de vítimas: o colapso do Estado e o papel das somalis na promoção da paz}

O regime cada vez mais repressivo de Siad Barre e as graves violações de direitos básicos levadas a cabo no norte do país acarretaram um crescente descontentamento e resistência contra o governo, provocando uma guerra civil total e o colapso do presidente em janeiro de 1991 (Horst, 2017). Ali Mahdi, do subclã Hawye, foi eleito presidente interino da Somália, ao passo que Mahmoud Farah Aidid, ex-general do governo Siad Barre, não reconheceu a nomeação e o país dividiu-se em dois setores hostis (Sitkowski, 2006). Ainda, após o colapso do Estado, a região noroeste da Somalilândia declarou a independência em maio de 1991 e embarcou em uma série de conferências de construção da paz que provaram ser bem-sucedidas na reintrodução da estabilidade na região (Horst, 2017).

Como mencionado anteriormente, na Somália os papeis e as posições das mulheres na sociedade têm sido historicamente definidos a partir da estrutura de clãs, bem como pelo sistema de direito consuetudinário e pela religião islâmica (Horst, 2017). Além das dinâmicas internas do país, a influência daqueles que migraram desde a eclosão do conflito têm também relevância central ao debate sobre o gênero na Somália. A diáspora somali no Oriente Médio, na Europa e na América do Norte desempenha um papel importante para o desenvolvimento político e sociocultural no país desde os anos 196o, e o regresso de um crescente número de mulheres da diáspora nos anos recentes tem contribuído para esta realidade (Horst, 2017).

Além disso, Ingriis e Hoehne (2013) observam que a guerra, apesar de suas nefastas consequências, apresentou oportunidades para as somalianas a partir de uma transformação das relações de gênero, principalmente no que concerne à economia. Devido ao impacto do conflito interno, a maioria das famílias - urbanas e rurais passaram a depender da produtividade econômica feminina em uma extensão muito maior que antes. E, enquanto no passado considerava-se vergonhoso que um homem dependesse financeiramente de sua esposa, em muitos lares, inclusive dentro da diáspora, as mulheres são agora as principais provedoras da família (El Bushra \& Gardner, 2004).

Sendo assim, a guerra não só causou danos, como também deu às somalianas a chance de assumir novos papéis. Algumas apoiaram ativamente e inflamaram a luta 
de seus parentes masculinos; outras até mesmo pegaram em armas e se tornaram combatentes. Porém, muitas mulheres também se voltaram para o trabalho de promoção da paz e da reconstrução da Somália (Ingriis \& Hoehne, 2013). Além disso, o fracasso contínuo dos protagonistas masculinos na política nacional abriu espaços para a discussão dos direitos das mulheres e seus papéis na política. Por volta de 2000, elas pareciam ter ganho cada vez mais confiança para desafiar os homens na política em vários níveis, e algumas garantiam assentos em conselhos locais, parlamentos regionais e nacionais, e até em cargos de gabinete. (Ingriis \& Hoehne, 2013).

Em sua definição mais básica, agência é a capacidade de agir. Na medida em que os indivíduos são capazes de agir, eles exercem alguma forma de agência. Em termos sociológicos, a capacidade de agir, no entanto, só pode ser entendida dentro do contexto de estruturas sociais específicas em determinados momentos e lugares, desde Estados, instituições sociais, grupos, cultura ou normas (Charrad, 2010). Mahmood (2001: 203) sugere que "pensemos em agência não como sinônimo de resistência a relações de dominação, mas como capacidade de ação que relações de subordinação historicamente específicas permitem e criam”.

As características multifacetadas e complexas da agência feminina estão, em parte, ligadas ao fato de que elas utilizam sua agência dentro dos limites das regras e dos recursos existentes. As mulheres levam em consideração valores sociais, significados e normas locais quando agem e iniciam uma mudança (Young, 1990). As principais estruturas que restringem a capacidade feminina em agir e transformar suas circunstâncias são normas patriarcais incorporadas em diversas instituições, como a família, o Estado, a religião, os tribunais e os mercados de trabalho (CHARRAD, 2010).

Assim, a agência da mulher precisa ser conceituada em relação às hierarquias de poder arraigadas na maioria as sociedades do mundo, bem como aos fatores de classe social, raça, etnia e o modo como a religião impacta na formulação de regras e normas. De acordo com Charrad (2010), a agência também é configurada em relação às estruturas de nível macro, como economia e política, bem como estruturas de nível micro, como as relações familiares e interpessoais. A agência ou subordinação feminina não pode ser imaginada fora das hierarquias de gênero estabelecidas e dos contextos institucionais e estruturais (Charrad, 2010). Assim como sugerido por Mohanty (1988), a posição exercida pela mulher na sociedade deve ser teorizada e interpretada a partir do âmbito de comunidades específicas; portanto, a atenção à conjuntura cultural, política, econômica e social que permitem à mulher somali o exercício de sua agência na construção da paz será devidamente tomada na dissertação.

A agência feminina no que tange as resoluções de conflitos e os processos de promoção da paz tem sido cada vez mais enfatizada em discursos políticos multilaterais. Com a Plataforma de Ação de Pequim em 1995, a qual clamava pelo aumento da participação feminina na resolução de conflitos a níveis decisórios, o Conselho de Segurança das Nações Unidas adotou sua primeira resolução com foco 
no papel das mulheres na manutenção da paz e segurança internacionais (Conselho de Segurança, 200o).

A Resolução 1325 do Conselho de Segurança sugere (1) um aumento na representação de mulheres no processo decisório relacionado à paz e a segurança, incluindo operações de paz da ONU; (2) proteção efetiva de mulheres e garotas sob o Direito Internacional Humanitário e os Direitos Humanos; e (3) atenção especial às mulheres no que diz respeito a justiça pós-guerra, o desarmamento e a desmobilização, além da repatriação e reintegração de refugiados (Conselho de Segurança, 2000). Um terço dos dezoito artigos da resolução é destinado para medidas que levem ao aumento da participação feminina nos processos de paz, nas negociações para a paz, nas operações de manutenção da paz, e como representativas especiais e enviadas do Secretário-Geral.

Diante desta conjuntura, Nakaya (2003) sugere que as mulheres devem ser centrais para o processo de paz, visto como podem trazer suas experiências à resolução de conflitos. Sendo assim, espera-se que elas articulem e negociem termos favoráveis para a equidade de gênero baseada em suas próprias experiências como chefes de família, líderes comunitárias, trabalhadoras humanitárias e sociais, e ativistas da paz. Ainda assim, a premissa da participação feminina como introdução à igualdade de gênero e acordos de paz sustentáveis ocorre de maneira lenta, posto que as mulheres continuam a ser discriminadas e marginalizadas na maior parte das sociedades pós-guerra (Nakaya, 2003).

Tradições patriarcais, estruturas estatais discriminatórias quanto ao gênero, a falta de incentivos por parte dos combatentes a comprometerem-se ao processo de paz, ou a indisponibilidade de recursos nacionais e internacionais para a implementação de acordos podem impedir uma efetiva participação feminina nos processos de construção da paz (Nakaya, 2003). Marginalizadas da arena masculina da política nacional, tendo ela suas bases no sistema patriarcal de clãs, no direito consuetudinário e na sharia, as somalianas direcionaram sua perspicácia política e agência coletiva para o espaço da sociedade civil, que se abriu após o colapso estatal.

El Bushra (2007) salienta que as somalianas e as organizações femininas estão sendo cada vez mais chamadas a intervir não apenas nas negociações de mediação e paz, mas também (e talvez particularmente) nos vários processos de reconstrução pós-conflito. As principais atividades das organizações de construção da paz na Somália consistem no fornecimento de necessidades básicas, como alimentos, abrigo e cuidados de saúde; na mediação em diversos níveis do conflito, incluindo a negociação formal da paz; no advocacy, onde trabalham pela sociedade civil com o governo provisório e a mídia para aumentar a conscientização sobre questões de direitos humanos em geral; e mais importante, a promoção da inclusão das mulheres na tomada de decisões na política (El Bushra, 2007).

Dentro das definições e limites um pouco incipientes da sociedade civil, as somalianas têm atuado como atores-chave e demonstrado uma forte liderança (Jama, 1991), em especial através do envolvimento em Organizações da Sociedade Civil (OSC). Na década de 1990, inspiradas pela Conferência de Pequim, dezessete 
organizações não-governamentais, a maioria liderada por mulheres, formaram uma organização guarda-chuva com o intuito de coordenar as atividades relacionadas à promoção da paz e fomentar o diálogo entre clãs. Assim nasce a Coalizão para Organizações de Base de Mulheres (COBA) como uma plataforma para construção da paz, que uniu vozes e esforços femininos. Ao conectar papeis específicos de gênero ao sistema de clãs, a Coalizão foi capaz de influenciar a base estrutural das relações de poder e conectá-la às iniciativas institucionais dos processos de paz (Nakaya, 2003). A COBA tem desde então trabalhado para promover os direitos das mulheres e apoiar vítimas de violência, porém sua principal contribuição para a construção da paz na Somália tem sido estimular o engajamento político das OSCs (Jama, 1991).

Em Mogadíscio, após diversas tentativas fracassadas para negociar um acordo de paz na década de 1990, a COBA arquitetou a criação da Rede de Paz e Direitos Humanos (RPDH), que consiste em um comitê de sete cidadãos em cada um dos dezesseis distritos na região de Banadir (incluindo Mogadíscio). Os comitês, apoiados por um grupo diversificado de atores da sociedade civil - incluindo ex-membros de milícias, mulheres, jovens, idosos e membros da mídia -, atuam como mediadores entre as regiões (University for Peace, 2004).

Os comitês são responsáveis por identificar as necessidades imediatas da população, conscientizar localmente essas necessidades e defender soluções coletivas para os problemas mais urgentes. Os comitês também mediam disputas de maneira não violenta e servem como uma equipe de alerta a possíveis conflitos. Muitas mulheres que trabalham nesses comitês constantemente cruzam a "Linha Verde", que metaforicamente divide Mogadíscio em dois campos hostis, para trabalhar pela paz e superar as diferenças entre clãs (University for Peace, 2004).

Em decorrência da COBA, um grande número de associações de mulheres e organizações de base (grassroot) foram criadas. Essas organizações trabalham dentro e entre afiliações de clãs, regiões e diversas classes socioeconômicas. Na Somália, atualmente, elas representam uma grande parte da assistência básica à saúde, à educação, ao treinamento vocacional para mulheres, entre outros serviços. O volume de organizações de mulheres proporcionou à Somália uma infraestrutura fundamental, embora alternativa e ad hoc, para a sobrevivência coletiva (UNINSTRAW, 2008).

No que tange a participação política, como apontado por Franceschet et al. (2012), as últimas duas décadas testemunharam ganhos sem precedentes no acesso feminino a cargos eleitos em todo o mundo, e isso é causado principalmente pela adoção de cotas de gênero. Tais cotas não aumentam apenas o número de mulheres em cargos políticos, mas também permitem diversificar os tipos de mulheres eleitas (incluindo, por exemplo, somalianas de diferentes clãs e classes), chamam atenção para as questões de gênero, mudam a natureza de gênero da esfera pública e inspiram as eleitoras femininas a se envolverem politicamente (Horst, 2017).

No entanto, a introdução da cota de gênero de 30\% na Somália (MUASOM, 2017), por si só, não se mostra suficiente para permitir uma representação feminina adequada na política. Em primeiro lugar, as cotas de gênero não são compatíveis 
com o sistema de cotas 4,5, em que os quatro grandes clãs somalis desfrutam de igualdade de posições políticas e uma variedade de clãs minoritários recebe uma parte do poder para distribuir entre si. Como apontado pelo estudo de Horst (2017) diversas somalianas argumentam que os clãs nunca desejariam que sua parcela de representação fosse para as mulheres.

Duas das principais questões a serem consideradas ao se analisar a participação política das somalianas no país são: em que medida a orientação sobre o papel feminino vem da religião e quais são as posições islâmicas em relação à participação política das mulheres; argumenta-se que os entendimentos atuais dos papéis de gênero na sociedade não são guiados pelo Islã, mas por práticas e atitudes culturais patriarcais (Mashhour, 2017). Como aponta Qaasim apud Horst (2017: 11), "práticas não-islâmicas foram integradas em várias culturas muçulmanas, tanto que muitos muçulmanos pensam que essas práticas são parte da religião. Portanto, é dessa maneira que surgem equívocos em torno da questão das mulheres no Islã".

Um argumento adicional frequentemente feito no debate sobre gênero, cultura e religião é que a versão do islamismo sunita que está se tornando cada vez mais prevalecente na Somália - que restringe o papel das mulheres à esfera privada - foi importada para a região dos países árabes. Essa tendência localiza-se no final dos anos 1970 e 1980, quando o descontentamento com o regime de Siad Barre e a crescente internacionalização de interpretações mais conservadoras do Islã influenciaram o poder crescente do direito religioso (Abdi, 2007).

\section{A interseccionalidade dos feminismos: as abordagens pós- coloniais, africanas e islâmicas no contexto da Somália}

Para o universo teórico tradicional das Relações Internacionais (RI), o estudo do poder tem sido central para a organização e produção do conhecimento dentro da disciplina. Tradicionalmente, o campo das RI lida em grande medida com as políticas das grandes potências e assuntos relacionados à segurança estatal. Em vista disso, as assimetrias de poder no âmbito político, econômico e social são muitas vezes negligenciadas nas teorias mainstream. Naturaliza-se assim as hierarquias de raça, etnia, gênero e classe, e reproduz-se o status quo das principais linhas de pensamento na disciplina.

É preciso reconhecer a forma como a interação destas questões (de raça, etnia, gênero, classe e o poder) trabalha na construção das dissimetrias no mundo globalizado (Chowdbry \& Nair, 2002). Surgem, então, obras de teóricos críticos que mudaram a orientação da produção do conhecimento em RI, de forma a considerar as diferentes configurações e efeitos da política internacional que articulam as desigualdades de poder (Agathangelou \& Turcotte, 2010).

Neste cenário, os estudos feministas tornaram o debate em RI mais aberto, pois assinalaram como as questões de gênero são intrínsecas à disciplina. A teoria 
feminista vincula o inquérito intelectual aos problemas críticos, e procuram problematizar a construção do conhecimento dentro do campo das RI. O gênero é um conceito desenvolvido a fim de contestar a naturalização das diferenças sexuais em diversas arenas da vida social e política; assim, as teorias e práticas feministas buscam explicar e mudar sistemas históricos de diferença sexual, nos quais "homens" e "mulheres" são socialmente constituídos e posicionados em relações de hierarquias e antagonismos (Nfah-Abbentyi, 2005: 259).

O foco principal dos feminismos tem sido em que medida os limites do Estado historicamente excluem as mulheres da vida política doméstica e internacional, e tratam as relações internacionais como domínio exclusivo dos homens e da masculinidade (Tickner, 2001). Assim como o terceiro debate nas RI, as teorias feministas também se envolveram em uma discussão crítica e na reavaliação de questões epistemológicas.

Esses debates iniciaram-se na década de 1960, quando as feministas radicais passaram a desafiar os fundamentos empiristas do feminismo liberal. Questionavase os pressupostos liberais de que a subordinação das mulheres poderia ser diminuída incorporando as mulheres nas estruturas institucionais existentes de forma igualitária aos homens (Tickner, 2001); porém, as feministas pós-liberais argumentavam que as estruturas hierárquicas deveriam ser radicalmente desafiadas a fim de abordar essas questões, e também demonstraram que o conhecimento sobre o mundo social e natural não é objetivo, mas baseado nas experiências dos homens (Tickner, 2001).

Conquanto que todas as formas de feminismos compartilham uma aspiração em comum de desmantelar sistemas sociais patriarcais que priorizam os interesses e autoridades do homem sobre a mulher, a primeira e a segunda onda do feminismo tenderam a normalizar as experiências de mulheres brancas, de classe média e ocidentais, ao mesmo tempo em que homogeneizavam as mulheres de outras categorias demográficas (Norwood, 2013).

Por conseguinte, os feminismos evoluíram para assumir diferentes significados, dependendo do contexto geográfico e cultural. Em alguns casos, como em nações em desenvolvimento, ex-colônias e entre populações marginalizadas no Ocidente, novas formas de feminismos surgiram para desafiar algumas das próprias suposições nas quais as feministas ocidentais se baseavam (Ngunjiri, 2013). Entre essas novas formas alternativas de pensamento estão os feminismos pós-coloniais, os feminismos africanos e os feminismos islâmicos que irão guiar a presente análise da experiência política das somalianas.

A escolha pelo feminismo pós-colonial diante do contexto da pesquisa dá-se pelo fato de que até mesmo a literatura feminista tradicional trabalha como fonte de opressão e colonização das mulheres do Sul Global. Em concordância com Tyagi (2014), as feministas Ocidentais são criticadas pela maneira orientalista com que representam as práticas sociais de outras raças como atrasadas e bárbaras, das quais a mulher negra/asiática/latina necessita salvação. $O$ feminismo Ocidental muitas vezes sofre de um viés etnocêntrico ao presumir que as soluções utilizadas pelas mulheres brancas Ocidentais para combater suas próprias opressões são igualmente 
aplicáveis a todas as outras mulheres. Como resultado, as questões de raça, etnia, classe e religião têm sido negligenciadas, impedindo que as feministas reflitam sobre as maneiras como o racismo e o patriarcado interagem (Tyagi, 2014).

Mostra-se necessário observar a localização estratégica ou situação da categoria "mulher" vis-à-vis o contexto da análise. A suposição da mulher como um grupo coerente e constituído, com interesses e desejos idênticos, independentemente de suas localizações quanto a raça, etnia, religiosidade ou classe, implica uma noção de gênero ou diferença sexual, ou até mesmo de patriarcado, que pode ser aplicado universalmente e interculturalmente (Mohanty, 19881: 64). O trabalho busca, portanto, atentar-se ao contexto cultural, político, econômico e social do objeto de análise - a mulher somali -, evitando generalizações.

Outra finalidade da teoria feminista pós-colonial à análise da experiência da mulher somali é desmantelar a categorização da "Mulher do Terceiro Mundo" como unicamente vítimas da violência masculina. Nesta categoria, como apontado por Mohanty (1988), as mulheres são sistematicamente definidas como as vítimas do controle masculino, ou seja, são sexualmente oprimidas. Apesar de ser verdade que o potencial masculino de ser violento contra a mulher circunscreve e elucida sua posição social em certo nível, definir as mulheres como vítimas arquetípicas as congela em "objetos que não conseguem defender a si mesmos" e os homens em "sujeitos que perpetram a violência", e toda sociedade em uma simples oposição entre grupos de pessoas impotentes (ou seja, a mulher) e poderosos (os homens) (Mohanty, 1998: 66-67).

A violência masculina deve ser teorizada e interpretada no contexto de sociedades específicas, tanto para melhor entendê-la quanto para que se possa organizar efetivamente para mudá-la (Mohanty, 1988). Como foi observado nas seções anteriores, a mulher somali exerceu um papel protagonista e assertivo nos principais processos da construção da política da Somália, e apesar de afligiremse com as estruturas patriarcais da sociedade clanista e do Estado, atuaram como importantes agentes históricos.

Não obstante, como apontado por Spivak (2010) a mulher é silenciada nas representações históricas devido ao seu papel marginal nas "listas de prioridades globais" (Spivak, 2010:126). O sujeito que é subalterno por pertencer às camadas mais baixas da sociedade é marginalizado e a situação é ainda mais árdua quando este sujeito é do gênero feminino, posto que "a mulher como subalterna, não pode falar e quanto tenta fazê-lo não encontra os meios para se fazer ouvir" (Spivak, 2010: 15). Assim, a mulher é impedida de se representar na história, e isto é exemplificado na realidade somali, onde a participação feminina nos processos políticos é negligenciada e muitas vezes ocultada.

As abordagens feministas africanas dialogam fortemente com as póscoloniais; de acordo com Norwood (2013), os feminismos africanos são um movimento intelectual e pragmático, surgido das experiências com o colonialismo, a escravidão e o patriarcado, e que tem como objetivo acabar com os sistemas interligados de opressões múltiplas. Refere-se, portanto, às experiências vividas e 
opressões compartilhadas pelas mulheres africanas, incluindo também movimentos sociais, políticos e culturais iniciados pelas mulheres (e homens) da diáspora, que explicitamente desafiam opressões sexistas e uma variedade de desigualdades (Norwood, 2009).

Embora as experiências das mulheres africanas sejam geograficamente diversas, a semelhança de suas lutas une-as de maneiras singulares. Norwood (2013) argumenta que o principal fator em comum entre as mulheres destas diversas regiões é a experiência compartilhada (e variada) da subjugação colonial. O colonialismo refere à exploração econômica, política e cultural de um país por uma nação estrangeira. Sob o colonialismo, a colônia é sistematicamente explorada, e os sistemas políticos e mercados nativos são destruídos, ao passo que uma nova economia é criada tanto dentro da colônia como globalmente (Norwood, 2013).

As experiências da mulher africana sob o colonialismo e os feminismos que são uma derivação desta experiência, são moldadas regionalmente de maneira única, ainda que similares. Assim, o feminismo africano, por natureza e circunstância, é fundamentalmente "desconstrutivista, inerentemente rebelde e assumidamente antiimperialista, anti-racista, anti-sexista, e (recentemente, desde a terceira onda) anti-homofóbico" (Norwood, 2013:226). Um objetivo comum dos feminismos africanos é, portanto, transformar a sociedade de modo que ela se torne uma civilização mais igualitária e justa para todas as pessoas.

Os feminismos africanos são difíceis de datar e de definir. Algumas estudiosas feministas africanas afirmam que as mulheres de África são as feministas originais (Adeleye-Fayemi, 2005; Steady, 1987). Para esse fim, posto que a África é o berço da civilização e da vida humana, ela também possui o mais antigo sistema de patriarcado e, consequentemente, a mais antiga luta contra tal sistema. E sugerir o contrário, aponta Adeleye-Fayemi apud Dosekun (2007: 43), é supor erroneamente que as mulheres africanas aceitaram passivamente o patriarcado por séculos.

Evidências da resistência das mulheres africanas ao patriarcado e ao colonialismo, em especial da mulher somali como exposto previamente, são abundantes e contradizem firmemente quaisquer estereótipos de passividade. Segundo Tripp et al. (2009), os movimentos de protesto das mulheres organizados em África datam a era pré-colonial; durante a era decolonial dos anos 1950 e 6o, o ativismo das mulheres africanas expressou-se largamente nas lutas de libertação nacional (Adpmako Ampofo, 2004), e as somalianas demonstraram ter sido fundamentais para a independência do país em relação ao imperialismo britânico e italiano.

Ademais, de acordo com Morell \& Ouzgane (2005: 5), durante a década de 1980 e 1990, os feminismos africanos também passaram a lançar uma forte crítica ao feminismo Ocidental. Construindo um legado de resistência às forças hegemônicas, as feministas africanas acusaram as teorias ocidentais de retratarem as mulheres africanas como vítimas indefesas e, em colaboração com outras feministas do Sul Global - como as pós-coloniais -, criticaram o feminismo ocidental por homogeneizálas e desconsiderar sua agência (Morell \& Ouzgane, 2005). 
Assim como as abordagens feministas islâmicas, nem todas as mulheres africanas aderem ao termo "feminista". Arndt (2002) argumenta que o termo feminismo, no contexto popular africano, é amplamente incompreendido e associado a versões radicais do feminismo Ocidental. O ceticismo direcionado ao termo, conforme expressado em estereótipos, tem levado à acusação popular de que o feminismo seria uma "invenção estrangeira”, cujas práticas ameaçariam os valores tradicionais africanos (Norwood, 2013: 228). Todavia, como indica Norwood (2013), este pensamento disseminado contra as correntes feministas africanas invalida séculos de movimentos de resistência feminina em todo o continente, além de reforçar argumentos essencialistas que defendem uma única identidade africana.

A relutância de algumas mulheres africanas em abraçar o rótulo "feminista" reflete suas críticas à hesitação das feministas ocidentais em enfrentar a opressão material, ir além da teoria e defender uma ideia universal de irmandade compartilhada, a despeito das desigualdades socioculturais (Norwood, 2009). Independentemente das perplexidades em nomear os feminismos, teóricas como Tamale (2006) argumentam que rejeitá-los significa essencialmente abandonar a possibilidade de mudança e verdadeira transformação.

Outro componente importante da plataforma feminista africana é desmascarar e desconstruir o imaginário Ocidental negativo de África e das mulheres africanas. No Ocidente, as mulheres africanas são muitas vezes retratadas como "impotentes", "subumanas, primitivas ehipersexuais", "sobrecarregadas com o lar e a domesticidade", sem a capacidade de determinar sua reprodução, submetendo-se deliberadamente ao domínio dos homens (Norwood, 2013, p. 228).

Além disso exposto, um cuidado metodológico que se deve ter em toda análise acerca das relações de gênero em uma sociedade é a consideração dos entendimentos locais sobre o significado de "igualdade de gênero" e "inclusão", visto que eles podem muitas vezes se diferenciar dos entendimentos de atores internacionais que buscam apoiar e promover sociedades mais igualitárias e inclusivas (Horst, 2017: 3). Os contextos "locais" não são realidades culturais estáticas, unificadas ou isoladas, dado que podem ser submetidas a inúmeras mudanças ao longo dos anos, em especial devido a influência do retorno de membros da diáspora e atores religiosos globais (Horst, 2017: 3), exemplificado pela mudança que as migrações e o aumento do extremismo sunita têm acarretado à Somália.

Sob condições de crise social sustentada, o gênero está sendo reconstruído sob a influência de determinadas comunidades religiosas e étnicas. Como consequência da guerra civil e de seus efeitos na Somália, as pessoas cujas vidas e meios de subsistência foram destruídas estão recorrendo a versões de religião que nunca fizeram parte de seu repertório cultural e tradicional (Abdi, 2007).

Quando a nação, grupo, tribo ou clã estão em crise, os papéis sociais das mulheres se tornam o ponto focal das construções identitárias masculinas. Os papéis e as práticas das mulheres também recebem atenção especial como símbolos da identidade do grupo. Assim, elas não apenas se tornam as primeiras vítimas de conflitos em termos da violência infligida a seus corpos e psiques; também carregam 
as consequências da guerra nos papéis e relações de gênero do pós-guerra dentro dessa sociedade (Abdi, 2007).

Tendo em vista esta mudança nos papeis de gênero na sociedade somali devido não apenas ao conflito, como também pela crescente incorporação de versões mais radicais do islã, o presente artigo utiliza vertentes dos feminismos islâmicos. Estas abordagens, assim como os feminismos pós-coloniais e africanos, combatem duas batalhas: uma contra homens orientados pelo patriarcado dentro do Islã e outra contra o feminismo ocidental, que possui uma atitude condescendente em relação ao islamismo (Ngunjiri, 2013).

A mulher muçulmana por excelência, muitas vezes representada pelo véu, existe no imaginário de muitas pessoas no mundo ocidental. Na realidade, como pondera Abdi (2007), mulheres muçulmanas em regiões muito diferentes do mundo expressam sua religião de maneiras híbridas, combinando costumes locais com os princípios do Islã. O islamismo local pressupõe características específicas da cultura, dependendo das condições de um determinado lugar e tempo (Abdi, 2007). O fato de o Islã praticado nessas regiões geograficamente e culturalmente distintas ser diversificado não deveria ser surpreendente. Os estudos sobre mulheres muçulmanas, no entanto, muitas vezes mascaram essa diversidade retratando uma visão monolítica e essencialista (Abdi, 2007), uma crítica sustentada também pelos feminismos pós-coloniais e africanos.

De acordo com Tomac (2011), as abordagens feministas islâmicas geralmente advogam pela igualdade de gênero no âmbito do Islã e em todas as esferas da vida, isto é, nos aspectos sociais, políticos e econômicos. A metodologia na aplicação desta abordagem implica a reinterpretação do Alcorão Sunnah (prática dos ensinamentos do Profeta Maomé) e do Alcorão Hadith (histórias do Profeta Maomé) através do que é chamado de ijtihad (investigação independente de fontes religiosas) e tafsir (interpretação do Alcorão).

$\mathrm{O}$ argumento subjacente é o de que a desigualdade de gênero em algumas sociedades mulçumanas decorre da interpretação equivocada dos ensinamentos islâmicos por indivíduos de mentalidade patriarcal. Deste modo, assim como os intérpretes masculinos construíram suas próprias interpretações de textos islâmicos e sancionaram a dominância masculina, também as intérpretes femininas podem contribuir imensamente para a desconstrução e o desafio do domínio masculino (Tomac, 2011).

Mashhour (2005) também defende que a deterioração dos direitos das mulheres em muitos países muçulmanos não está relacionada à natureza islâmica, $\mathrm{e}$ que a maioria das desigualdades de gênero não é baseada no Islã; esta deterioração, portanto, seria o resultado de práticas patriarcais. Por consequência, essas sociedades aplicam interpretações conservadoras e literais de vários textos do Alcorão ou abstraem certas passagens de seus contextos para justificar sua dominação sobre as mulheres (Mashhour, 2005). Ainda, Tahir-ul-Qadri (2011) argumenta que a igualdade de gênero é fundamental e faz parte da jurisprudência dos ensinamentos islâmicos. 
A desigualdade de gênero na maioria das sociedades muçulmanas não é, destarte, baseada na fé.

Como Deniz Kandiyoti (1991, p. 185) observa,

Diferentes sistemas de dominância masculina e suas variações internas, de acordo com a classe e a etnia, exercem uma influência que flexiona e modifica a prática real do Islã, bem como a construção ideológica do que pode ser considerado como sendo propriamente islâmico (Kandiyoti, 1991).

Independentemente das variações islâmicas praticadas em sociedades geograficamente distantes e culturalmente distintas, um aspecto comum em muitas destas sociedades é o aumento contínuo de uma interpretação conservadora do Alcorão, ou o que alguns chamam de direita religiosa (Iman, 200o) ou de movimento fundamentalista (Moghissi, 200o). Embora a diversidade exista dentro desse movimento, as características compartilhadas pela maioria dos conservadores religiosos incluem um projeto de reconstrução de uma sociedade islâmica "não manchada por influências coloniais e ideias modernas" (Iman, 2000: 127).

A interpretação islâmica conservadora que está sendo importada à Somália reconfigura práticas culturais e religiosas preexistentes; alega-se que essas comunidades têm praticado erroneamente e, portanto, se desviado do verdadeiro Islã (Abdi, 2007). Abdi (2007) ressalta que a maioria das mulheres, e a sociedade somali em geral, viram o novo conservadorismo como um desafio à sua liberdade de movimento, associação e vestuário, um desafio à autonomia que as mulheres herdaram de sua cultura nômade e transplantaram para os centros urbanos. A guerra civil somali, então, catalisou uma alteração dramática da representação pública e da identidade islâmica das mulheres somalis (Abdi, 2007).

\section{Considerações Finais}

Ainda que a sociedade somali esteja alicerçada em pressupostos altamente patriarcais, as mulheres foram capazes de participar ativamente da economia e da política do país. Fosse de maneira menos assertiva através de poemas, ou mais incisivamente por manifestações da Liga da Juventude Somali, a mulher desempenhou um papel decisivo na promoção de uma consciência nacionalista ao longo da história da Somália. Durante o período colonial com a Liga da Juventude Somali, elas estiveram envolvidas na organização e recrutamento de novos membros ao partido, promovendo sentimentos nacionalistas, arrecadando fundos e cobrando taxas de adesão, habitando e escondendo os nacionalistas das autoridades, e participando de manifestações (Aidid, 2011). 
Com o golpe militar de Siad Barre em 1969, o governo socialista identificou as mulheres como uma base de apoio forte e as mobilizou politicamente. Ainda que sua participação fosse modesta, as mulheres foram capazes de manipular algumas medidas governamentais a seu favor através do apoio ao Estado. A guerra civil que assolou o país após a derrubada de Siad Barre no começo dos anos 1990 modificou drasticamente a estrutura da sociedade somali. Muitos autores argumentam que a guerra, apesar de suas nefastas consequências, apresentou oportunidades para as mulheres a partir de uma transformação das relações de gênero, principalmente no que concerne à economia.

Devido ao impacto da guerra, a maioria das famílias - urbanas e rurais passaram a depender da produtividade econômica das mulheres em uma extensão muito maior que antes. E, enquanto no passado era vergonhoso que um homem dependesse financeiramente de uma mulher, em muitos lares, inclusive dentro da diáspora, as mulheres são agora as principais provedoras da família. Na última década, as mulheres em toda a Somália estiveram profundamente envolvidas na promoção da paz do país. Além de exercer influência em privado sobre seus maridos, filhos, irmãos e tios - os meios tradicionais que as mulheres podem usar para influenciar a tomada de decisões políticas -, elas se organizaram e exerceram influência coletiva na comunidade a um nível mais amplo. As importantes contribuições das mulheres para acabar com a violência e a promoção da paz incluíram apresentações formais às partes em guerra, manifestações, ações diretas, e fornecimento de apoio logístico e financeiro aos processos de paz.

Ainda que a participação da mulher somali seja ativa e constante nos âmbitos políticos e econômicos, diversos fatores contribuem para o silêncio dessa atuação tanto nas bibliografias locais e regionais, quanto internacionais. O extremismo religioso cada vez mais presente na Somália tem contribuído para a dificuldade das mulheres em impor na prática seus direitos constitucionais de participação igualitária na política. Ainda que haja a previsão de uma cota de 30\%, a hierarquização da sociedade patriarcal além da falta de mecanismos institucionais para sua aplicação faz com que a atuação na esfera pública ainda seja restrita. Porém, como um instrumento de luta contra estas estruturas, é preciso cada vez mais evidenciar e enaltecer o ativismo feminino somali para que, logo, essa realidade seja revertida.

\section{Referências}

ABDI, Cawo Mohamed. Convergence of Civil War and the Religious Right: Reimagining Somali Women. Signs, v. 33, n. 1, 2007, pp. 183-207.

ADAN, Abdullahi. Clan Politics in Somalia: Consequences of culture or colonial legacy? 2015. Disponível em: <http://somalithinktank.org/wp-content/uploads/2015/o9/ Clan_Politics-final.pdf> Acesso em: 7 de janeiro de 2018. 
ADELEYE-FAYEMI, Bisi. Creating and Sustaining Feminist Space in Africa: Local and Global Challenges in the 21st Century. In ROCCOITELLI, Luciana et. al. Feminist Politics, Activism and Vision: Local and Global Challenges. London, New York: Zed Books, 2005.

ADOMAKO AMPOFO, Akosua. Women's and Gender Studies in English-Speaking Sub-Saharan Africa, A Review of Research in the Social Sciences. Gender and Society, v. 18, n. 6, 2004, pp. 685-714.

AIDID, Safia. "Haweenku Wa Garab" (Women are a Force): Women and the Somali Nationalist Movement, 1943-1960. Bildhaan: An International Journal of Somali Studies. v. 10., n. 1., 2011 pp. 103-124.

AGATHANGELOU, Anna;TURCOTTE, Heather. Postcolonial Theories and Challenges to 'First World-ism'. In: SHEPHERD, Laura. Gender Matters in Global Politics: A feminist introduction to international relations. Nova York: Routledge, 2010, pp. 5558.

AL-SHARMANI, Mulki. Living Transnationally: Somali Diasporic Women in Cairo. International Migration, v. 44, n. 1, 2006, pp. 55-77.

AMIN-KHAN, Tariq. The Post-Colonial State in the Era of Capitalist Globalization: Historical, Political and Theoretical Approaches to State Formation. Londres e Nova York: Routledge, 2012.

AMISOM. Somali Women's Participation in Politics and Public Life. 2016. Disponível em: $\quad$ http://amisom-au.org/wp-content/uploads/2016/12/Somali-WomensParticipation-in-Politics-and-Public-Life.pdf> Acesso em: 25 de fevereiro de 2018.

ARNDT, Susan. The Dynamics of African Feminism: Defining and Classifying African Feminist Literatures. Trenton: Africa World Press, 2002.

BANCO MUNDIAL. Wold Bank Makes Progress to Support Remittance Flows to Somalia, 2018. Disponível em: <http://www.worldbank.org/en/news/pressrelease/2016/o6/10/world-bank-makes-progress-to-support-remittance-flows-tosomalia> Acesso em: 23 de março de 2018.

BANERJEE, Sikata. Gender and Nationalism: The masculinization of hinduism and female political participation in India. Women's Studies International Forum, v. 26, n. 2, 2003, pp. 167-179.

BBC NEWS. Who are Somalia's al-Shabab? 2017. Disponível em: <http://www.bbc. com/news/world-africa-15336689> Acesso em: 31 de março de 2018. 
BREYDEN, Matt; STEINER, Martina. Somalia between peace and war: Somali women on the eve of the 21st century. UNIFEM, 1998.

CHARRAD, Mounira. Women's agency across cultures: Conceptualizing strenghts and boundaries. Women's Studies International Forum, v. 33, 2010, pp. 517-522.

CHOWDBRY, Geeta; NAIR, Sheila. Power, Postcolonialism and International Relations. London and New York: Routledge, 2002.

DOSEKUN, Simidele. Defending Feminism in Africa. Postmable, v. 3, n. 1, 2007, pp. 41-47.

EL BUSHRA, Judy. Feminism, Gender, and Women's Peace Activism. Development and Change, v. 38, n. 1, 2007, pp. 131-147.

EL BUSHRA, Judy; GARDNER, Judith. The Untold Story: The war through the eyes of somali women. London: Pluto Press, 2004.

FARAH, Abdulkadir. Diaspora involvement in the development of Somalia. Aalborg: Institut for Historie, Internationale Studier og Samfundsforhold, Aalborg Universitet, 2009.

FOREIGN POLICY. The Most Dangerous Place in the World, 2009. Disponível em: <http://foreignpolicy.com/2009/o9/30/the-most-dangerous-place-in-the-world/> Acesso em: 29 de janeiro de 2018.

FRANCESCHET, Susan; KROOK, Mona; PISCOPO, Jennifer. The Impact of Gender Quotas. New York:Oxford University Press, 2012.

GROVOGUI, Siba. Postcolonialism. In: DUNNE, Tim; KURKI, Milja; SMITH, Steve. International Relations Theories: Discipline and Diversity. Oxford: Oxford University Press, 2013.

HORST, Cindy. Somali debates on women's public roles and political participation. Journal of Eastern African Studies, v. 11, n. 3, 2017, pp. 389-407.

HUMAN RIGHTS WATCH. Here, Rape is Normal: a five-point plan to curtail sexual violence in Somalia, 2014. Disponível em: <https://www.hrw.org/report/2014/o2/13/ here-rape-normal/five-point-plan-curtail-sexual-violence-somalia $>$ Acesso em: $29 \mathrm{de}$ janeiro de 2018. 
IMAN, Aisha. 2000. The Muslim Religious Right ('Fundamentalists') and Sexuality. In ILKKARACAN, Pinar. Women and Sexuality in Muslim Societies. Istanbul: Women for Women's Human Rights, 2000.

INGRIIS, Mohamed Haji. 'Sisters, was this what we struggled for?': The Gendered Rivalry in Power and Politics. Journal of International Women's Studies, v. 16, n. 2, 2015, pp. 376-394.

INGRIIS, Mohamed; HOEHNE, Markus. The impact of civil war and state collapse on the roles of Somali women: a blessing in disguise. Journal of Eastern African Studies, v. 7, n. 2, 2013, pp. 314-333.

JAMA, Zainab. Fighting to Be Heard: Somali Women's Poetry. African Languages and Cultures, v. 4, n. 1, 1991, pp. 43-53.

JAMA, Fazia. Whose peace is it anyway? Connecting Somali women and international peacemaking. Accord, v. 21, 2010, pp. 62-65.

JIBRIL, Hawa. And Then She Said: The Poetry and Times of Hawa Jabril. Toronto: Jumblies Press, 2008.

KANDIYOTI, Denis. Islam and Patriarchy: A Comparative Perspective. In KEDDIE, Nikki. Women in Middle Eastern History: Shifting Boundaries in Sex and Gender. New Haven: Yale University Press, 1991.

MAHMOOD, Saba. Feminist theory, embodiment, and the docile agent: some reflections on the Egyptian Islamic revival. Cultural Anthropology, v. 6, n. 2, 2001, pp. 202-236.

MASHHOUR, Amira. Islamic Law and Gender Equality: Could There be a Common Ground? Human Rights Quarterly, v. 27, n. 2, 2005, pp. 562-596.

MCCLINTOCK, Anne. "No Longer a Future Heaven”: Gender, Race and Nationalism. In: MCCLINTOCK, Anne; MUFTI, Aamir; SHOHAT, Ella. Dangerous Liaisons: Gender, Nation, and Postcolonial Perspectives. Minneapolis: University of Minnesota Press, 1997.

MOHAMED, Hamdi. Multiple Chalanges, Multiple Struggles: A History of Somali Women's Activism in Canada. 2003. Tese (Doutorado em História) - Faculty of Graduate and Postdoctoral Studies, University of Ottawa, Ottawa, Canada.

MOHAMED, Iman. Somali Women and the Socialist State. Journal of Georgetown University-Qatar, v. 4, 2015, pp. 1-10. 
MOHANTY, Chandra. Under Western Eyes: feminist scholarship and colonial discourses. Feminist Review, n.30, Autumn, 1988, pp. 61-88.

MOGHISSI, Haideh. Feminism and Islamic Fundamentalism: The Limits of Postmodern Analysis. London: Zed, 2000.

MORELL, Robert; OUZGANE, Lahoucine. African Masculinities, Men in Africa from the Late Nineteenth Century to the Present. Nova York: Palgrave, 2005.

MUZURANA, Dyan; PROCTOR, Keith. Gender, Conflict and Peace. Occasional Paper, World Peace Foundation, October 2013.

MWANGI, Oscar Gakuo. State Collapse, Al-Shabaab, Islamism, and Legitimacy in Somalia. Politics, Religion \& Ideology, v. 13, n. 4, 2012, pp. 513-527.

NAKAYA, Sumie. Women and Gender Equality in Peace Processes: From Women at the Negotiating Table to Postwar Structural Reforms in Guatemala and Somalia. Global Governance, v. 9, n. 4, 2003, pp. 459-476.

NFAH-ABBENYI, Juliana. Gender, Feminist Theory, and Post-Colonial (Women's) Writing. In OYEWUMI, Oyeronke. African Gender Studies: A reader. Basingstoke: Palgrave Macmillan, 2005.

NJOKU, John E. Eberegbulam. The World of the African Woman. Metuchen: Scarecrow Press, 1980.

NGUNJIRI, Anne Wangui. The Role of "Islamic feminism" in Somali Immigrant Women's Intra-and Extra-Household Bargaining Power and in Mitigating the Negative Effects of the Image Problem in their Integration in Norway. 2013. Dissertação (Mestrado em Gênero e Desenvolvimento). Faculty of Psychology, Universidade de Bergen, Bergen, Noruega.

PEW RESEARCH CENTER. 5 facts about the global Somali diaspora, 2016. Disponível em: <http://www.pewresearch.org/fact-tank/2016/o6/o1/5-facts-about-the-globalsomali-diaspora/> Acesso em: 23 de março de 2018.

PNUD. Ending Gender Based Violence in Somalia, 2017. Disponível em: <http://www. so.undp.org/content/somalia/en/home/blog/2017/11/27/Ending-Gender-BasedViolence-in-Somalia-.html. Acesso em: 29 de janeiro de 2018.

RYDLOVA, Barbora. Civil War in Somalia: a colonial legacy? 2007. Dissertação (Mestrado em Ciência Política) - Institut Politologických Stydií, Univerzita Karlova, Praga, República Checa. 
SAMATAR, Abdi Ismail. Leadership and ethnicity in the making of African state models: Botswana versus Somalia. Third World Quarterly, v. 18, n. 4, 1997, pp. 687708.

SITKOWSKY, A. UN Peacekeeping: Myth and Reality. Praeger Security International, 2006.

SPIVAK, Gayatri. Pode o Subalterno Falar? Belo Horizonte: Editora UFMG, 2010.

TAHIR-UL-QADRI, Muhammad. Gender Equality and Islam. Minhaj-ul-Quran International (MQI): Women League, 2011.

TAMALE, Sylvia. African Feminism: How Should we change? Development, v. 49, n.1, 2006, pp. 38-41.

TOMAC, Ayca. Debating 'Islamic Feminism': Between Turkish Secular Feminist and North American Academic Critiques. 2011. Dissertação (Mestrado em Arte). Department of Gender Studies, Queen's University, Ontario, Canada.

TRIPP, Ali Mari et. al. African Women's Movements, Changing Political Landscapes. New York, NY: Cambridge University Press, 2009.

TYAGI, Ritu. Understanding Postcolonial Feminism in relation with Poscolonial and Feminist Theories. International Journal of Language and Linguistics. v. 1, n. 2, 2014, pp. 45-50.

UN-INSTRAW. Women, Peace and Security in Somalia: Implementation of UN Security Council Resolution 1325. UN-INSTRAW Background Paper, 2008.

UNSOM. Somali religious scholars defend 30 percent quota for women. 2016. Disponível em: <https://reliefweb.int/report/somalia/somali-religious-scholarsdefend-30-percent-quota-women>. Acesso em: 31 de março de 2018.

YOUNG, Iris. Justice and the Politics of Difference. Princeton: Princeton University Press, 1990.p. 45-50. 